\title{
Nasal carriage of Staphylococcus aureus in Australian (pre-clinical and clinical) medical students
}

\author{
E. Stubbs, M. Pegler, A. Vickery * and C. Harbour
}

Department of Infectious Diseases, The University of Sydney, Sydney 2006 NSW, Australia and * Department of Microbiology, Royal Prince Alfred Hospital (RPAH), Camperdown 2050, Australia

\author{
Accepted for publication 3 Fanuary 1994
}

\begin{abstract}
Summary: The nasal carriage of Staphylococcus aureus in 808 Australian medical students was studied. Five groups of students experienced varying degrees of clinical exposure in a hospital environment ranging from 0 to 42 months. The overall percentage of carriers among the five groups did not vary. However, with increasing clinical exposure there was a decrease in the percentage of isolates sensitive to all antibiotics tested, and an increase in the carriage of $S$. aureus resistant to three or more antibiotics. No carriers of methicillin-resistant $S$, aureus (MRSA) were detected. The comparative rates of $S$. aureus carriage between female and male students varied. The relevance of medical students as nasal carriers of $S$. aureus in the hospital environment today is discussed.
\end{abstract}

Keywords: Medical students; Staphylococcus aureus; nasal carriage.

\section{Introduction}

Nosocomial infections due to Staphylococcus aureus have become an increasing problem over the last four decades. ${ }^{1}$ Antibiotic resistance is seen in most strains, and in some Australian hospitals the proportion of methicillin-resistant $S$. aureus (MRSA) has been reported to be $25 \%$ of all staphylococcal isolates. ${ }^{2}$ The remaining $75 \%$ of staphylococcal isolates show varying antibiotic resistance. Few nosocomial strains today are sensitive to all antibiotics; the majority range from resistant to penicillin only, to resistant to two or more antibiotics. A contributing factor to the problem of nosocomial infections is the nasal carriage of $S$. aureus among hospital personnel. ${ }^{3}$

This reservoir of potential pathogens has been recognized as a significant source for new carriers among patients and staff. ${ }^{3}$ The carriage of $S$. aureus in patients is associated with an increased risk of infection. In general the carriage rate for all $S$. aureus among hospital personnel has been reported from different countries as constant over the decades. For example, a British 
study in 1955 reported the rate to be $35 \%{ }^{4}$ in a study in the US in 1969 , the rate was $39 \%{ }^{5}$ and in a 1991 Nigerian study it was also $39 \%,{ }^{6}$ but higher carriage rates for non-MRSA have been reported during epidemics. ${ }^{7}$ However, nasal carriage rates of MRSA have been found to be lower, ranging from 1 to $6 \%{ }^{8}$ and in 1985 Cafferkey et al. reported $4 \%$ of staff involved in an outbreak of MRSA as carriers. ${ }^{9}$

There have been few recent studies on the nasal carriage of $S$. aureus among medical students. A study of medical undergraduates at Trinity College, Dublin, in 1983, with differing periods of hospital exposure showed no change in carriage rates; however, there was a trend towards more antibiotic resistance in the group with longer exposure. ${ }^{10}$ In 1990 , a study of Polish medical undergraduates showed a carriage rate of $33 \%$ with low antibiotic resistance. ${ }^{11}$ Non-medical undergraduates in Nigeria were reported to have a carriage rate of $56.4 \%$ with a considerable proportion of the strains resistant to commonly used antibiotics. ${ }^{12}$ To determine if increased exposure to Australian hospital environments in 1990-1991 affected nasal carriage of $S$. aureus, we studied five groups of medical students attending Sydney University, with pre-clinical and clinical exposure.

\section{Materials and methods}

\section{Students}

Eight hundred and eight students were included in the study. Five student groups were sampled with a response rate ranging from 90 to $100 \%$. The groups were as follows: Group A, in which 193 of 209 first year medical students with no clinical exposure were sampled. This group was the pre-clinical group and was considered to be representative of the general community; Group B, in which 195 of 201 third year medical students, enrolled in 1990, who had been exposed to a hospital environment for one day per week for 6 months, were sampled; Group C, in which 169 of 177 fourth year medical students, enrolled in 1990, were sampled. In addition to clinical exposure in their third year, these students had been exposed to a hospital environment for an additional 2 days per week for 12 months; Group D was 206 of 229 fourth year medical students, enrolled in 1991, with the same length of clinical exposure as Group C. Group D included a core of 164 students who had been sampled previously in Group B in 1990. This sub-group of 164 students was also the subject of a longitudinal study. Finally Group E was 45 interns, commencing at a teaching hospital. These graduates, having completed 6 years as medical students, had been in a hospital environment for 42 months.

The ratio of female to male students in the five groups was (A) $1: 1 \cdot 7$, (B) $1: 2 \cdot 1$, (C) $1: 1 \cdot 8$, (D) $1: 2 \cdot 2$, (E) $1: 2 \cdot 0$.

\section{Microbiology}

Nasal swabs. Nasal swabs were taken with a peptone water-moistened swab 
Table I. Prevalence of nasal carriage and antibiotic resistance of Staphylococcus aureus in Australian medical students

\begin{tabular}{|c|c|c|c|c|c|c|c|}
\hline \multirow[t]{2}{*}{$\begin{array}{l}\text { Student } \\
\text { group }\end{array}$} & \multirow{2}{*}{$\begin{array}{l}\text { Number } \\
\text { of } \\
\text { students }\end{array}$} & \multirow{2}{*}{$\begin{array}{l}\text { Clinical } \\
\text { exposure } \\
\text { in months }\end{array}$} & \multirow{2}{*}{$\begin{array}{l}\text { Carriers } \\
\text { of } \\
\text { S. aureus } \\
\text { No. }(\%)\end{array}$} & \multicolumn{4}{|c|}{$\begin{array}{l}\text { No. of antibiotics to which the } \\
\text { S. aureus strains (\%) were resistant }\end{array}$} \\
\hline & & & & 0 & 1 & 2 & $>3$ \\
\hline $\mathrm{A}$ & 193 & $\mathrm{Nil}$ & $68(35 \cdot 2)$ & $19(27.9)$ & $40(58 \cdot 8)$ & $8(11 \cdot 8)$ & $1(1 \cdot 5)$ \\
\hline $\mathrm{B}$ & 195 & 6 & $83(42 \cdot 6)$ & $13(15 \cdot 7)$ & $56(67 \cdot 4)$ & $10(12 \cdot 1)$ & $4(4 \cdot 8)$ \\
\hline $\mathrm{C}$ & 169 & 18 & $64(37.9)$ & $9(14 \cdot 1)$ & $44(68 \cdot 7)$ & $8(12 \cdot 5)$ & $3(4 \cdot 7)$ \\
\hline $\mathrm{D}$ & 206 & 18 & $87(42 \cdot 2)$ & $8(9 \cdot 2)$ & $58(66 \cdot 7)$ & $16(18 \cdot 4)$ & $5(5 \cdot 7)$ \\
\hline $\mathrm{E}$ & 45 & 42 & $18(40 \cdot 0)$ & $2(11 \cdot 0)$ & $12\left(66^{\circ} 7\right)$ & $3(16.7)$ & $1(5.6)$ \\
\hline
\end{tabular}

from the right and left anterior nares of each student by the same operator, and plated immediately onto blood agar plates. After $18 \mathrm{~h}$ incubation at $37^{\circ} \mathrm{C} \mathrm{S}$. aureus isolates were identified by routine microbiological methods, including coagulase production and production of DNAase. All S. aureus isolates were characterized by their antibiograms and phage sensitivity. ${ }^{2}$

Antibiograms. Antibiotic sensitivity was determined by the replica plate method. ${ }^{13}$ Antibiotics tested were $(\mathrm{mg} / 1)$ : penicillin $(0 \cdot 125)$, methicillin $(4 \cdot 0)$, erthromycin $(1 \cdot 0)$, tetracycline $(4 \cdot 0)$, chloramphenicol $(8 \cdot 0)$, fusidic acid $(1 \cdot 0)$, rifampicin $(0 \cdot 125)$, vancomycin $(4 \cdot 0)$, trimethoprim $(1 \cdot 0)$, gentamicin $(2 \cdot 0)$, novobiocin $(2 \cdot 0)$. Results were read after $18 \mathrm{~h}$ incubation at $37^{\circ} \mathrm{C}$. An additional set of methicillin plates was incubated at $30^{\circ} \mathrm{C}$. Isolates were considered resistant if more than three colonies of visible growth were present.

Phage typing. All strains were phage typed according to the methods described by Blair and Williams, ${ }^{14}$ using casamino yeast extract agar with the Basic International set of Typing Phages plus two experimental phages 90 and 88. Phages were used at routine test dilution (RTD) and $100 \times$ RTD.

Statistical analysis. Data were analysed by using the $\chi^{2}$ test with Yates's correction or Fisher's test of exact probability where appropriate.

\section{Results}

Table I shows the prevalence of nasal carriers in the five groups: pre-clinical Group A, 35.2\% and clinical Groups B, $42 \cdot 6 \%$, C, $37.9 \%, D, 42 \cdot 2 \%$, and E, $40.0 \%$. A total of $320 \mathrm{~S}$. aureus strains were isolated. With increasing clinical exposure there was a decrease in the number of students carrying isolates of $S$. aureus sensitive to all 11 antibiotics tested: $27.9 \%(19 / 68)$ in Group A, 15.7\% (13/83) in Group B, 14.1\% (9/64) in Group C, 9.2\% (8/87) in Group D and $11.0 \%(2 / 18)$ in Group E. The percentage of strains 


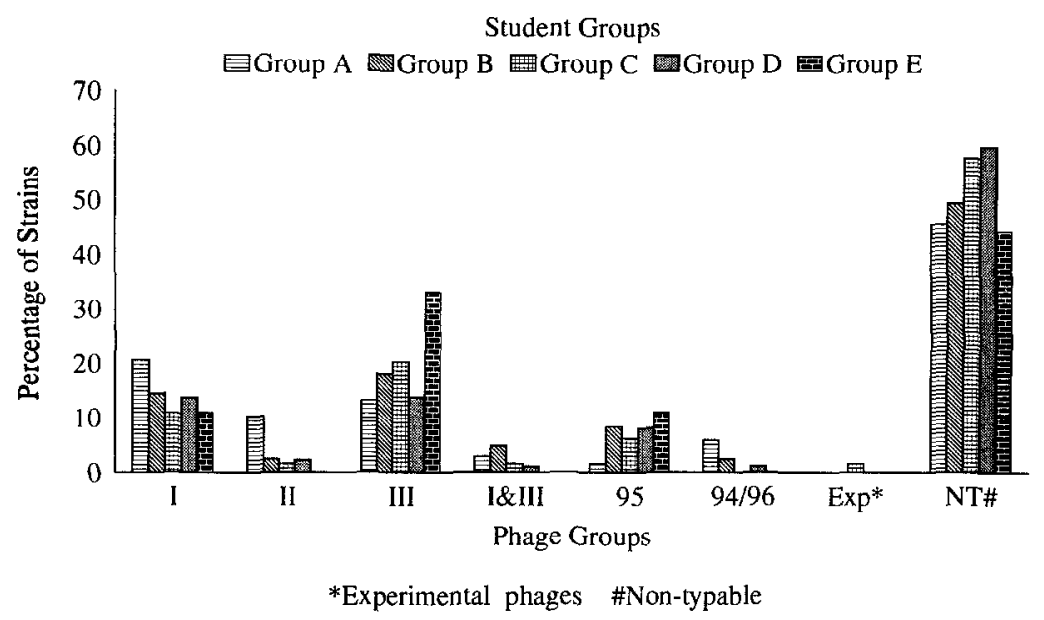

Figure 1. Phage group distribution of strains in student groups, when phage typed at routine test dilution.

resistant to penicillin alone showed an increase from $58.8 \%$ in pre-clinical Group A to greater than $66.7 \%$ in the clinical groups $(P>0.05)$. There was also a marked increase in strains resistant to three or more antibiotics from $1.5 \%$ in pre-clinical Group A to $5.7 \%$ in the clinical groups $(P>0.05)$.

All 320 isolates were phage typed. One hundred and fifty-one $(47 \cdot 2 \%)$ were typable at RTD using the Basic International Set of Typing Phages. The majority of these strains belonged to either phage group I $(31 \cdot 1 \%)$ or phage group III $(36.4 \%)$, while $14.0 \%$ of strains typed as phage typc 95 and $4 \cdot 6 \%$ typed as phage type $94 / 96$. Eight per cent typed at RTD as phage group II strains. Overall there was a general distribution of these phage type patterns, but the pre-clinical Group A had the highest proportion of phage group I strains $(20.6 \%)$, while strains of phage group III were predominant $(33.3 \%)$ among the clinical Group E (Figure 1).

When the 169 non-typable strains were retyped at $100 \times$ RTD using the Basic International Set, $27(16.0 \%)$ typed as phage group I, $48(28.4 \%)$ as phage group II, $18(10 \cdot 7 \%)$ as phage group III and $63(37 \cdot 3 \%)$ remained non-typable. Variation in the distribution of these phage types between the student groups showed an increase in phage group II strains from $22.6 \%$ in pre-clinical Group A to $50.0 \%$ in clinical Group E, and a decrease in non-typable strains from $48.4 \%$ in Group A to $25.0 \%$ in Group E (Figure 2).

Analysis of the data from the sub-group of 164 Group D students tested in 1990 , and retested in 1991 , showed that $52(31.7 \%)$ remained carriers, $37(22.6 \%)$ changed their carrier status, being identified as transient carriers, either gaining or losing nasal carriage of $S$. aureus and $75(45 \cdot 7 \%)$ remained non-carriers (Table II). 


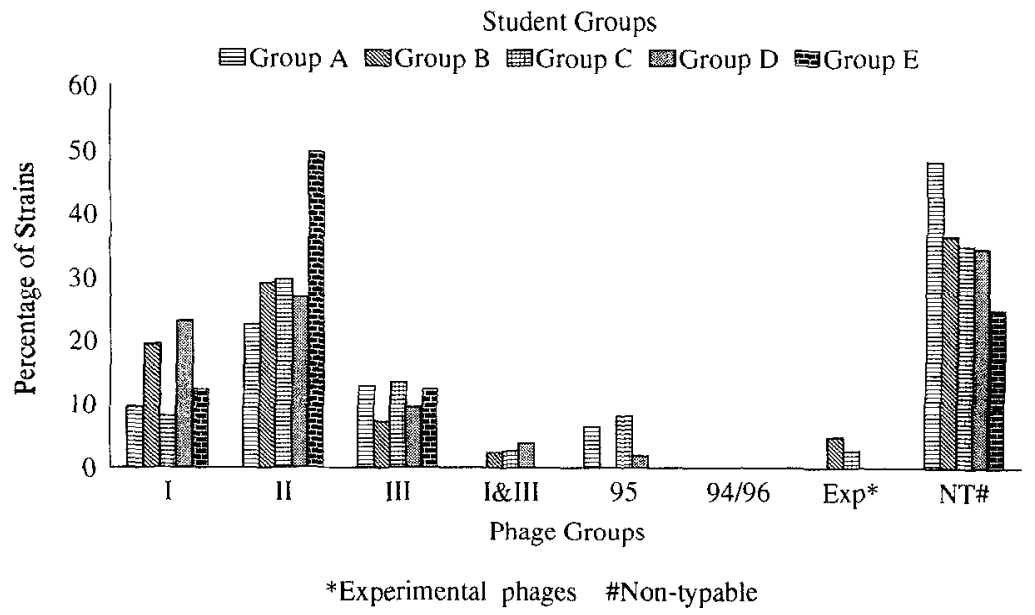

Figure 2. Phage group distribution of strains in student groups, when re-phage typed at $100 \times$ routine test dilution.

Table II. Staphylococcus aureus carrier state of 164 medical students sampled in 1990 and 1991

\begin{tabular}{|c|c|c|c|c|c|}
\hline \multirow[t]{4}{*}{$\begin{array}{l}\text { Anlibiotic } \\
\text { sensitivity } \\
\text { of strains }\end{array}$} & \multicolumn{5}{|c|}{$\begin{array}{c}\text { Carrier state } \\
\text { No. }(\%)\end{array}$} \\
\hline & \multicolumn{2}{|c|}{$\begin{array}{c}\text { Persistent carrier } \\
52(31.7)\end{array}$} & \multicolumn{2}{|c|}{$\begin{array}{l}\text { Transient carrier } \\
(37(22 \cdot 6)\end{array}$} & $\begin{array}{c}\text { Non-carrier } \\
75(45 \cdot 7)\end{array}$ \\
\hline & $\begin{array}{l}\text { Carrying } \\
\text { original } \\
\text { strain }\end{array}$ & $\begin{array}{c}\text { Carrying } \\
\text { new strain }\end{array}$ & $\begin{array}{l}\text { Acquisition } \\
\text { of strain }\end{array}$ & $\begin{array}{l}\text { Loss of } \\
\text { strain }\end{array}$ & \\
\hline & $\begin{array}{r}38(73 \cdot 1) \\
5(13 \cdot 2)\end{array}$ & $\begin{array}{r}14(26 \cdot 9) \\
1(7 \cdot 2)\end{array}$ & $\begin{array}{r}18(48 \cdot 7) \\
2(11 \cdot 1)\end{array}$ & $\begin{array}{r}19(51 \cdot 3) \\
3(15.8)\end{array}$ & - \\
\hline $\mathrm{PR}+$ & $23(60 \cdot 5)$ & $10(71 \cdot 4)$ & $11(61 \cdot 1)$ & $13(68 \cdot 4)$ & - \\
\hline$\geqslant 2 \mathrm{R}$ & $10(26 \cdot 3)$ & $3(21 \cdot 4)$ & $5(27 \cdot 8)$ & $3(15 \cdot 8)$ & - \\
\hline
\end{tabular}

* Sensitive to all antibiotics; $\nmid$ Resistant to penicillin only; $₫$ Resistant to two or more antibiotics.

Of the 52 students who remained carriers, $38(73 \cdot 1 \%)$ continued to carry their original strain. Twenty-three $(60.5 \%)$ of these strains were resistant to penicillin only, $10(26 \cdot 3 \%)$ were resistant to two or more antibiotics, and five $(13 \cdot 2 \%)$ were sensitive to all antibiotics tested.

When the 38 strains were phage typed, $14(36 \cdot 8 \%)$ belonged to phage group I, five $(13.2 \%)$ were phage type $95,13(34.2 \%)$ belonged to phage groups II or III and six $(15.8 \%)$ were non-typable. Fourteen $(26.9 \%)$ of the 52 students remained carriers but acquired a different strain. Ten $(71.4 \%)$ of these strains were resistant to penicillin only, three $(21.4 \%)$ were resistant 
Table III. Comparison of Staphylococcus aureus carriage rates between male and female students

\begin{tabular}{ccccc}
\hline $\begin{array}{c}\text { Student } \\
\text { group }\end{array}$ & $\begin{array}{c}\text { Clinical } \\
\text { exposure in } \\
\text { months }\end{array}$ & \multicolumn{3}{c}{ No. of students $(\%$ carriers) } \\
\cline { 3 - 5 } & & Female & Male & $P$ value* \\
\hline A & Nil & $69(31 \cdot 9)$ & $124(37 \cdot 1)$ & $0 \cdot 57$ \\
B & 6 & $63(42 \cdot 9)$ & $132(42 \cdot 4)$ & $0 \cdot 92$ \\
C & 18 & $60(20 \cdot 0)$ & $109(47 \cdot 7)$ & 0.0007 \\
D & 18 & $64(35 \cdot 9)$ & $142(45 \cdot 1)$ & $0 \cdot 28$ \\
E & 42 & $15(53 \cdot 3)$ & $30(30 \cdot 0)$ & $0 \cdot 23$ \\
\hline${ }^{*} \chi^{2}$ & & & & \\
\end{tabular}

to two or more antibiotics and one $(7.2 \%)$ was sensitive to all antibiotics tested. No one phage type predominated among these 14 strains.

In the transient carrier group 37 students, $18(48.7 \%)$ became carriers. $11(61 \cdot 1 \%)$ of the acquired strains were resistant to penicillin only, five $(27 \cdot 8 \%)$ were resistant to two or more antibiotics and three $(11 \cdot 1 \%)$ were sensitive to all antibiotics tested. The remaining 19 students in the transient group became non-carriers. Thirteen $(68.4 \%)$ of the strains that were lost were resistant to penicillin only, three $(15.8 \%)$ were resistant to two or more antibiotics and three $(15 \cdot 8 \%)$ were sensitive. There was no one phage group that predominated among these 19 strains (Table II).

The carrier rates among female and male students in Groups A, B, D and E showed no significant difference (Table III). The rates were $31.9 \%$ and $37.1 \%$ in Group A, $42.9 \%$ and $36.8 \%$ in Group B, 35.9\% and $45.1 \%$ in Group D and $53.3 \%$ and $30.0 \%$ in Group E respectively. However, a significant difference $(P=0.0007)$ was observed in Group C where $20.0 \%$ of female students were carriers compared with $47.7 \%$ of male students.

\section{Discussion}

This study details the effect of exposure to the hospital environment, in 1990-91, on the nasal carriage of $S$. aureus among Australian medical students. Although the prevalence of nasal carriage was found to be similar in the pre-clinical and clinical groups, the carriage of strains of $S$. aureus resistant to three or more antibiotics increased from $1.5 \%$ in the pre-clinical group to $5 \cdot 7 \%$ in the clinical groups.

The antibiotic resistance and phage-typing patterns of $S$. aureus carried by the students, particularly strains of phage groups II and III, reflect those of current nosocomial isolates in Sydney teaching hospitals (A. Vickery, unpublished observations). The carriage of phage group II strains was an interesting observation. In the past, strains of phage group II have been regarded as 'community-strains', but there has been an increase in recent years in the isolation of phage group II strains from clinical specimens in 
Sydney teaching hospitals. This trend has also been reported in Danish hospitals where phage group II strains have increased in incidence from $13.6 \%$ in 1983 to $18.8 \%$ in $1988 .^{15}$

Nasal carriage of MRSA in hospital personnel has been reported to be low ${ }^{16}$ with higher carriage rates reported when there has been an outbreak of MRSA infections. ${ }^{9}$ No carriers of MRSA were detected among the students in this study although MRSA made up to $25 \%$ of all staphylococcal isolates in the hospitals the students attend for their clinical experience. Reasons for the lower carriage rate of MRSA have been sought by studying their ability to establish nasal carriage, but Ward ${ }^{17}$ showed that MRSA and methicillin-sensitive $S$. aureus have an equal likelihood of nasal carriage.

Previous studies have shown that people may be persistent nasal carriers, persistent non-carriers or transient carriers of $S$. aureus. ${ }^{18}$ The data from the sub-group of 164 students in this study showed similar findings. The carriage and acquisition of strains resistant to two or more antibiotics observed in this group reflect the non-MRSA staphylococcal population in the hospital's environments.

A higher nasal carriage rate of $S$. aureus by female subjects aged over 20 years, than by male subjects has been reported in a survey of Nigerian students. ${ }^{12}$ In another study, female patients on continuous ambulatory peritoneal dialysis were also shown to have a higher carriage rate than the male patients. ${ }^{3}$ In our study female students in Group $\mathrm{C}$ had a significantly lower carriage rate than their male counterparts; however in Group E a higher carriage rate was observed among the the female students although this was not statistically significant. Variation in carriage rates in female subjects has been reported to be associated with oestrogen levels as measured by the karyopknotic index (KI). ${ }^{19}$ This factor was not investigated in this study but may offer an explanation for the variation observed.

Since the carriage of $S$. aureus in the nares and on the skin contribute to the problem of nosocomial infections ${ }^{20}$ medical students as nasal carriers of nosocomial strains remain a potential source of cross-infection in the hospital environment today. This study highlights the importance of ongoing education of hospital personnel regarding cross-infection in order to help eliminate costly and preventable morbidity.

\section{References}

1. Wise RI, Ossman EA, Littlefield DR. Personal reflections on nosocomial staphylococcal infections and the development of hospital surveillance. Rev Infect Dis 1989; 2: 1005-1019.

2. Vickery AM, Pegler MA. Changes in phage-typing patterns of methicillin-resistant Slaphylococcus aureus strains isolated in New South Wales, Australia. In: Jeljaszewicz J, Ciborowoski P, Eds. The Staphylococci Zbl Bakt Suppl. 21. Stuttgart: Verlag Gustav Fischer 1991; 386-387.

3. Luzar MA, Coles GA, Faller B, et al. Staphylococcus aureus nasal carriage and infection in patients on continuous ambulatory peritoneal dialysis. $N$ Engl $\mathfrak{F}$ Med 1990; 322: 505-509. 
4. Blowers R, Mason GA, Wallace KR, Walton M. Control of wound infection in a thoracic surgery unit. Lancet $1955 ; 2$ : 786-794.

5. Maxwell JG, Ford CR, Peterson DE, Mitchell CR. Long-term study of nasal staphylococci among hospital personnel. Am F Surg 1969; 118: 849-854.

6. Ako-Nai AK, Torimiro SE, Lamikanra A, Ogunniyi AD. A survey of nasal carriage of Staphylococcus aureus in a neonatal ward in Ile-Ife, Nigeria. Ann Trop Paediatr 1991; 11: 41-45.

7. Rountree PM, Beard MA. Further observations on infection with phage type 80 staphylococci in Australia. Med F Aust 1958; 2: 789-795.

8. Boyce JM. Should we vigorously try to contain and control methicillin-resistant Staphylococcus aureus? Infect Control Hosp. Epidemiol 1991; 12: 46-54.

9. Cafferkey MT, Hone R, Coleman D, Pomeroy H, McGrath B, Ruddy R, Keane CT. Methicillin-resistant Staphylococcus aureus in Dublin 1971-84. Lancet 1985; 2: 705-708.

10. Kingdom JCP, Joyce SM, Bradley FL, Jauch W, Falkiner FR, Keane CT. Staphylococcal nasal carriage in medical students with varying clinical exposure. $\mathcal{F}$ Hosp Infect 1983; 4: 75-79.

11. Rafalowska K, Caban J, Chmielak A, Harasim A, Stefanska K, Topa I. Staphylococcus aureus carriers status of medical students. In: Jeljaszewicz J, Ciborowski P, Eds. The Staphylocci, Zhi Bakt Suppl 21. Stuttgart: Gustav Fischer Verlag 1991; 437-438.

12. Lamikanra A, Paul BD, Akinwole OB, Paul MO. Nasal carriage of Staphylococcus aureus in a population of healthy Nigerian students. F Med Microbiol 1985; 19: 211-216.

13. Washington JA, Sutter VL. The dilution susceptibility test: Agar and macrobroth dilution procedures. In: Lennette EH, Balows A, Hausler WJ, Truant PJ, Eds. Manual of Clinical Microbiology, Washington, DC: American Society for Microbiology 1980; $453-458$.

14. Bair JE, Williams REO. Phage typing of staphylococci. Bull WHO 1961; 24: 771-784.

15. Rosdahl VT, Bentzon MW. Epidemiological studies of Staphylococcus aureus strains in Danish hospitals in the period 1975-1988. In: Jeljaszewicz J, Ciborowski P, Eds. The Staphyloccus Zhl Bakt Suppl, 21. Stuttgart: Gustav Fischer Verlag. 1991; 465-470.

16. Casewell MW. Epidemiology and control of the 'modern' methicillin-resistant Staphylococcus aureus. F Hosp Infect 1983; 7: (Suppl.A): 1-11.

17. Ward TT. Comparison of in vitro adherence of methicillin-sensitive and methicillin-resistant Staphylococcus aureus to human nasal epithelial cells. F Infect Dis 1992; 166: 400-404.

18. Williams REO. Healthy carriage of Staphylococcus aureus: its prevalence and importance. Bacteriol Rev 1963; 27: 56-71.

19. Winkler J, Block C, Leibovici L, Faktor J, Pitlik SD. Nasal carriage of Staphylococcus aureus: Correlation with hormonal status in women. F Infect Dis 1990; 162: 1400-1402.

20. Noble WC, Williams REO, Jevons MP, Shooter RA. Some aspects of nasal carriage of staphylococci. F Clin Path 1964; 17: 79-83. 